\title{
INTERFACES EM EDUCAÇÃO E COMUNICAÇÃO: PERSPECTIVAS PEDAGÓGICAS PARA A ESCOLA CÍVICO-MILITAR
}

\section{ARTIGO ORIGINAL}

SANTOS, Luiz Ricardo dos ${ }^{1}$, DEDONÉ, Tiago Silvio²

SANTOS, Luiz Ricardo dos. DEDONÉ, Tiago Silvio. Interfaces em educação e comunicação: perspectivas pedagógicas para a escola cívico-militar. Revista Científica Multidisciplinar Núcleo do Conhecimento. Ano 06, Ed. 05, Vol. 13, pp. 111 122. Maio de 2021. ISSN: 2448-0959, Link de acesso: https://www.nucleodoconhecimento.com.br/educacao/perspectivas-pedagogicas, DOI: 10.32749/nucleodoconhecimento.com.br/educacao/perspectivas-pedagogicas

\section{RESUMO}

A presente pesquisa tem como objetivo possibilitar uma reflexão sobre as interfaces entre os campos da comunicação, educação, tecnologias e Segurança Pública, proporcionando, como processo de metodologia, um paralelo entre a teoria da Educomunicação, que trata das ações de emancipação social, cultural e educacional dos educandos que têm acesso aos mecanismos de comunicação, como rádio, internet, jornal impresso, revistas, produtos de audiovisuais, curta metragens em sala de aula, e os aspectos que se relaciona como as propostas pedagógicas de uma escola cívico-militar. Com isso, possibilita uma dinamização do processo de ensino aprendizagem, já que estes recursos são atrativos e eficazes. O presente artigo busca, através das referências bibliográficas e sob o aporte da intersecção entre os campos da comunicação, educação e tecnologias, contribuir com o debate e o fomento de projetos relacionados à formação em espaços das Escolas CívicoMilitares. Durante a abordagem da pesquisa é possível observar as fundamentações epistemológicas que dão aporte ao processo de construção destas teorias que se

\footnotetext{
${ }^{1}$ Pós-graduado em Direito Militar, Direito Ambiental, Armazenagem de grãos e Segurança Alimentar, Gestão Ambiental, Logística, Bacharel em Administração de Empresas e Administração Rural, cursando Agronomia.

${ }^{2}$ Orientador. Mestrado em andamento em Teoria Literária.
}

Disponível em: https://www.nucleodoconhecimento.com.br/educacao/perspectivaspedagogicas 
convergem, bem como os debates sobre as alternativas de leituras subjetivas para implementação nos espaços das Escolas. Portanto, a metodologia utilizada é a análise bibliográfica, subsidiando as reflexões. As reflexões aportadas na obra buscam destacar que o advento da inserção da comunicação nos espaços da educação formal nas escolas cívico-militares, proporcionam ampliação de ecossistemas comunicacionais e, com isso, dinamizar não apenas o aspecto da interação nestes espaços educativos, como, também, uma possibilidade para novos formatos no sistema pedagógico.

Palavras-chave: Educomunicação, Escola Cívico-Militar, Tecnologias Educacionais, Legislação Educacional.

\section{INTRODUÇÃO}

A presente pesquisa tem como meta compreender os processos que permeiam pela interface entre a comunicação e a educação, dentro das unidades educativas, como forma de dinamização do processo de ensino aprendizagem. Ou seja, o uso dos diversos mecanismos de comunicação para facilitar a aplicação pedagógica. E tem um objeto definido: as instituições educativas Cívico-Militares. Nesta reflexão, buscase explicar o papel das novas tecnologias como recursos dinamizadores que podem ajudar a construir reflexões, planejamentos pedagógicos e novos paradigmas discursivos para o campo da educação. Para tanto a pesquisa nos leva à teoria da Educomunicação, proposta criada pelo Núcleo de Comunicação e Educação da Universidade de São Paulo (NCE / USPE), que pode ser uma ponte para a implementação de didáticas e experiências exitosas.

O que se observa nas escolas é muitos casos de exclusão de crianças e adolescentes com dificuldade de aprendizado. Várias são as hipóteses, entre as quais, a necessidade de modernização de sistemas de ensino. A Educomunicação contribui para 0 enriquecimento do processo de ensino e aprendizagem, possibilitando uma ampliação do ambiente comunicacional, onde estes educandos passam a se socializar mais, resultando em progressos significativos, podendo até 
reverter o quadro dos que apresentam problemas de aprendizagem, e por conta disso são indisciplinados. Além disso, ajudam a formar alunos-cidadãos críticos, ativos diante do que consomem nos produtos midiáticos, éticos na sociedade em que figuram. Desta forma, com expertise em leitura crítica e ampliação informacional.

Aporta-se no conceito da Educomunicação como

[...] o conjunto das ações inerentes ao planejamento, implementação e avaliação de processos, programas e produtos destinados a criar e a fortalecer ecossistemas comunicativos em espaços educativos presenciais ou virtuais, assim como a melhorar o coeficiente comunicativo das ações educativas, incluindo as relacionadas ao uso dos recursos da informação no processo de aprendizagem. Em outras palavras, a Educomunicação trabalha a partir do conceito de gestão comunicativa. A comunicação precisa ser planejada, administrada e avaliada, permanentemente.(SOARES, 2000, p. 65).

Um fator de complexidades de aprendizagem que se observa muito durante as aplicações educomunicativas é a carência afetiva, advinda, muitas vezes, das complexas relações familiares. Segundo Wallon (1968), o desenvolvimento de uma pessoa é visto como uma construção progressiva em que se sucedem fases com que destaquem possibilidades no campo da afetividade e, também, da cognição. Ele explica que no estágio da adolescência, por exemplo, há a predominância das complexas afetividades, além do âmbito da construção de sentidos através do embate das idéias, pensamentos, leituras de mundo. Por isso, também, o presente trabalho permeia por esta reflexão, já que trabalhar os campos da psicologia da comunicação e a construção / manifestação da subjetividade, aliado à expressividade do protagonismo na construção dos discursos e as propostas de ações possíveis nas escolas cívico-militares, são nortes essenciais para o desenvolvimento educacional.

Ao entender as interfaces possíveis entre a educomunicação e mostrar que uma comunicação de qualidade é capaz de levar o sujeito a alcançar o seu melhor, a se desenvolver, construímos um novo paradigma. Decodificando os motivos das dificuldades de aprendizagem e os fatores que o limitam, muitas vezes encontrados

Disponível em: https://www.nucleodoconhecimento.com.br/educacao/perspectivaspedagogicas 
nos espaços escolares experiências formativas que que lutam para alcançar emancipação no letramento - não apenas da norma culta, mas, também, um letramento subjetivo, visando alcançar o desenvolvimento de um trabalho pedagógico eficaz.

Hoje em dia, principalmente na rede pública e municipal, são observados diversos fatores que limitam o desenvolvimento de um trabalho de qualidade pelo professor. Entre estas dificuldades, destaque para: as salas superlotadas, infraestrutura inadequada (às vezes sem ventiladores, com carteiras quebradas, lousas em más condições), falta de recursos, baixos salários dos professores e demais profissionais do setor, o mau comportamento dos alunos, manifestações de violências diversas, o enfrentamento às drogas, sistema pedagógico que nem sempre contemplam aspectos como novas tecnologias e modernizações. É uma luta diária. Estes são alguns dos elementos que acabam prejudicando e até mesmo impossibilitando o rendimento eficaz na sala de aula.

Em um ambiente superlotado, com a desestrutura de equipamentos e recursos, além de outras complexidades, é tarefa difícil para o professor perceber e respeitar as individualidades do aluno, dedicando-se de forma efetiva a cada um deles, promovendo uma atenção diferenciada, ação esta que é muito importante para o desenvolvimento cognitivo.

Outra questão problemática encontrada em salas superlotadas é a falta de controle do professor sob a classe, uma explicita deficiência no ecossistema comunicacional do espaço educativo, o que acaba resultando em tensões e conflitos em detrimento do mal comportamento e indisciplina. Num ambiente que apresenta estas características fica cada vez mais complexo promover aulas que incentive a construção e a troca de conhecimentos. Ambientes onde a comunicação é rica e democrática e onde existe uma boa infraestrutura que ofereça conforto e segurança os alunos, professores e família, instigam aplicações pedagógicas de qualidade. 
Naturalmente é um processo perceptível o fato de que fica agravada a situação dos alunos quando eles não se sentem bem e confortáveis no ambiente de estudo. Calor excessivo, carteiras que não são adequadas, lousas em que não se pode enxergar o que é escrito pelos professores, materiais não modernos e conteúdo didático pouco atrativo e que nem sempre se associa com a realidade externa vivenciada pelos alunos, são fatores que dispersam a atenção do conteúdo que está sendo transmitido, o que acaba resultando em baixo processo de absorção dos conhecimentos e emancipação. Ferreira (2000) nos expressa que este cenário físico não é neutro, imparcial, pois ele propaga constantemente, experiências de sentidos, mensagens subjetivas às crianças. $O$ autor destaca que estes cuidados podem estar aportados em atenção ao processo de desenvolvimento, quanto, também, pode deixar de expressar estes mesmos interesses de atenção.

Diante desta linha reflexiva, a abordagem do trabalho se propõe a explicar o que é educomunicação e qual a sua relação com um sistema de gestão pautado pelas escolas cívico-militares, a importância do processo dialógico na construção do conhecimento do aluno e como a relação dos campos da comunicação, educação e segurança podem convergir para emancipação de projetos pedagógicos eficazes. Nesta vertente, a educomunicação pode se firmar como uma ferramenta em que o objetivo de trabalhar a construção das subjetividades, valorizando-as e oportunizando espaços para a criatividade através de diversos mecanismos da comunicação audiovisual, radiofônica, jornal e revista impressa, internet, são elementos agregadores para a dinamização do processo de ensino-aprendizagem.

Como relatado anteriormente, é justamente por haver muitos crianças e adolescentes que se encontram excluídas por apresentarem dificuldades na leitura, escrita, expressão e socialização, que o estudo desta interface objeto desta reflexão se faz importante. Também se faz estratégico o fato desta proposta estar relacionada com a perspectiva de gestão das Escolas Cívico - Militares, que, inclusive, muitos cidadãos direcionam argumentos preconceituosos, justamente por não compreenderem a importância estratégica, social e psicossocial na vida de crianças, adolescentes e famílias. Em relação a este debate, Lima (2015) enaltece 
que o objetivo das escolas com contribuições dos militares é o de formar cidadãos disciplinados. Vasconcelos (1994) também destaca a importância desta vertente da formação, e informa que a escola também é um espaço de trabalho coletivo, que se prospecta ações de interação. Para permear pelo campo reflexivo dos benefícios de um espaço como a Escola Cívico - Militar, Ferreira (2018) nos lembra que o fato das escolas permearem por uma gestão ambígua, onde advém contribuições das áreas da Educação e da Segurança Pública, ajudam a consolidar e estruturar este tipo de oferta educacional. Santos (2006, p. 01), declara que estas " instituições responsáveis por essa atividade atuam no sentido de inibir, neutralizar ou reprimir a prática de atos socialmente reprováveis, assegurando a proteção coletiva, e por extensão, dos bens e serviços".

O presente artigo poderá servir como aporte epistêmico para que seja direcionado um olhar de atenção para os aspectos positivos deste fenômeno de parceria entre a escola, a família, a comunidade, e as contribuições dos agentes públicos de segurança. Busca-se uma relação positiva de intersecção, visando que os estudos encontrem e abordem a questão da convergência entre estes campos do conhecimento tão ricos em possibilidades para ampliação do sistema de ensino eficaz. Vale destacar que a educomunicação é uma área de conhecimento relativamente nova, entretanto, ela se despontava como um recurso didático importante para a ampliação da expressão criativa. Usando os recursos midiáticos para facilitar o processo. Construindo mídias em sala de aula e associando com a prática pedagógica. A partir dos conceitos e práticas da educomunicação pode-se trabalhar aspectos como enfrentamento a violências, a autoestima e a aprendizagem efetiva e criativa do aluno, pois estes estarão inseridos na produção de meios de comunicação que já estão presentes no dia-a-dia deles.

Dois pólos de reflexão aportam-se, até aqui. O Primeiro, a perspectiva da nova escola, mais moderna, interativa, atenta às novas tecnologias, focada no progresso e desenvolvimento de competências e habilidades dos alunos na nova geração. Outro segundo, a missão que a escola, a família e os demais agentes de uma sociedade têm de pavimentar caminhos para o enfrentamento à criminalidade na 
escola, a desatenção, indisciplina, falta de estrutura e valorização dos professores, entre outros aspectos. É justamente neste viés que a proposta da Educomunicação para as Escolas Cívico-Militares se faz estratégica, já que busca ampliar o processo dialógico, respeitar e incentivar a expressão e o desenvolvimento de competências. Portanto, a inter-relação entre os campos da Comunicação e Educação, duas áreas do saber tão complementares e, ao mesmo tempo, tão antagônicas, têm buscado despertar, ao longo das últimas décadas, uma multiplicidade de pesquisas e discussões acerca de suas respectivas interfaces e significativas contribuições no processo de construção do conhecimento. Estes campos possuem características específicas que, por si só, interessam a todas as demais atividades humanas. Imagina, portanto, a dimensão de possibilidades quando relacionadas.

\section{DESENVOLVIMENTO: OS DEBATES SOBRE A INTERSECÇÃO DE CAMPOS E A APROXIMAÇÃO COM O CONTEXTO MILITAR}

Entendendo um estágio no qual a comunidade escolar se configura como um local de constante criação e recriação da cultura, de um ambiente que concretize a troca social de sentidos e de valores, propondo paradigmas, pode averiguar que, este processo só é possível, graças aos resultados obtidos por meio dos caminhos interlocutivos e dialógicos. Nesta ótica, fundamenta-se, a necessidade de a comunidade escolar rever seu papel dentro do cenário social e apropriar-se, cada vez mais, da consciência transformadora a qual acredita-se que traga enraizada em sua essência.

A necessidade de convergência entre os campos da comunicação, educação e novas tecnologias, visando a proteção das crianças/adolescentes e o pleno desenvolvimento do processo de atenção aos alunos, já vem se firmando como pauta de pesquisa há muitas décadas, ainda que de maneira mais intuitiva e não tão sistematizada. Para Ângela Schaun (2002) o avanço dos meios de comunicação contribuiu sistematicamente com o desenvolvimento de um novo e legítimo campo de convergência de saberes, em que o percurso da educação para a comunicação, ou da comunicação para a educação, passou a ser um campo que perpassa as diversidades aparentes.

Disponível em: https://www.nucleodoconhecimento.com.br/educacao/perspectivaspedagogicas 
A comunicação é fator prioritário para o processo educativo e a mediação dos dois campos deve ser compreendida enquanto construção de valores éticos e estéticos. Aprender é também um processo coletivo, respeitando - se as diferenças e valorizando a criação, produção e alimentação de projetos geradores de transformação social (SCHAUN, 2002, p. 79).

O pesquisador Adilson Citelli afirma que as perspectivas deste campo de convergência, enaltecendo a necessidade de reconhecer as possibilidades de ampliação dos fluxos democratizadores na circulação das mensagens, é uma prática necessária emergente e cada vez mais presente no contexto educacional.

Assim, não perdemos a perspectiva segundo a qual as instituições comunicacionais e escolares tornaram-se lugares interdiscursivos que operam diálogos entre si, independentemente das possíveis assimetrias e desigualdades em suas condições de força. (CITELLI, 1999, p. 146).

Para Soares a relação destas áreas da comunicação, educação, entre outros, vem mobilizando a articulação de um fenômeno, um novo campo. "A educação para a comunicação, o uso das tecnologias na educação e a gestão comunicativa transformam-se em objeto de políticas educacionais, sob a denominação comum de Educomunicação" (SOARES, 2000).

Devemos analisar o papel que as tecnologias e as informações/imagens têm articulado no campo das reconfigurações de paradigmas discursivos transversos, instigando novas metodologias, novos formatos de construção de pontes, os quais chamamos de ecossistemas comunicacionais, além, claro, das inserções didáticas usufruindo as tecnologias. Pela perspectiva que percebemos a escola, hoje, tem exercido um papel de denunciar os meios de comunicação social, cremos que esse seja o papel da escola. Porém sua função também é a de apresentar estas metodologias participativas na construção de conhecimentos. Rego (2004), portanto, permeia por esta reflexão ao destacar os nortes de Vygostky, os quais "o ser humano não só é um produto de seu contexto social, é também um agente ativo na criação deste contexto" . 
Por meio destes aspectos reflexivos explicitados neste artigo, temos a compreensão de que as características apresentadas vêm ao encontro da do que a área da educomunicação poderia propor para estes espaços educativos. A Implementação de ações educativas que proporcionam a dinamização do processo de ensino e aprendizagem faz-se importante pois traz alternativas de ampliação dialógica e de uso de recursos da tecnologia para aportar-se neste viés de novos rumos. Numa ação educomunicativa, o aluno vai elaborar hipóteses, perguntas, realizar pesquisas, elaborar o projeto e entender, a partir desse processo e por meio do mediador como se movimenta "as mídias " e toda a cultura de massa no processo de manipular a população para "comprar" suas ideias, produtos etc. Desta forma, o aluno passa a desenvolver sua criticidade, a socialização e o cognitivo.

A educomunicação na instituição escolar possibilita situações de ensino que permitem aos alunos a realização de novas atividades e faz com que cada indivíduo seja o protagonista de sua aprendizagem e protagonista do processo construção do seu conhecimento, pois passa a dar valor ao protagonismo do aluno, sua disponibilização criativa. Isso caracteriza-se como subjetividade humana. $\mathrm{O}$ embate subjetivo entre os atores, possibilita crescimento e novos conhecimentos

Vygotsky afirma que as características tipicamente humanas não estão presentes desde o nascimento do indivíduo, nem são mero resultados das pressões do meio externo. Elas resultam da interação dialética do homem e seu meio sociocultural. Ao mesmo tempo em que o ser humano transforma o seu meio para atender suas necessidades básicas, transforma-se a si mesmo. (REGO, 1995, p. 49)

Portanto, esta conexão de paradigmas que busca a modernização do sistema de ensino, acoplado a contribuição da família, da escola, na perspectiva da segurança, inclusive com a inserção militar no âmbito da referência de formação cidadã, firmase como aspecto importante.

Analisamos, anteriormente, a perspectiva epistêmica que se aporta na intersecção entre os campos da comunicação, educação, novas tecnologias e a segurança pública. O ponto de reflexão desta convergência é a teoria da Educomunicação, que

Disponível em: https://www.nucleodoconhecimento.com.br/educacao/perspectivaspedagogicas 
chama a atenção para o direcionamento de ótica sobre a importância de alfabetização midiática, de infraestrutura moderna, de planejamento estratégico que interligue o aspecto conceitual da missão educativa, com o aspecto conceitual da missão social. Ambos os aspectos, permeando pela qualificação de expectativas de educação transformadora.

Mas, afinal, qual o conceito histórico-social da Escola Cívico - Militar? O Governo Federal instituiu o Decreto №10.004, de 05 de setembro de 2019, que trata da criação do Programa Nacional das Escolas Cívico-Militares - PECIM. O objetivo é instigar a melhoria na qualidade da educação básica no ensino fundamental e no ensino médio. Desenvolvido pelo Ministério da Educação com o apoio do Ministério da Defesa, este formato e sistema educativo está sendo implementado em colaboração com os Estados, os Municípios e o Distrito Federal na promoção de ações destinadas ao fomento e ao fortalecimento das Escolas Cívico-Militares. De acordo com a Portaria № 2.015, de 20 de novembro de 2019, o programa passou a ser regulamentado. Diante disso, Estados e municípios do país já passaram a aderir este sistema, em sistema consulta popular à comunidade escolar.

Acerca do processo de estruturação deste programa, sua estruturação deu-se início no início de 2019, com a implementação da Subsecretaria de Fomento às Escolas Cívico-Militares, órgão responsável por pesquisar, fomentar e implementar este modelo de escola âmbito nacional.

Na perspectiva Cívico - Militar, os agentes de segurança pública contribuem com a escola, principalmente, no âmbito da gestão do espaço e na formação cidadã. Não há influência na gestão pedagógica, educativa, mas, sim, no cuidado com o espaço, na formação cidadã, com projetos de civismo e até mesmo na seara da representação social, transmitindo referência de segurança e respeito. Este aporte colaborativo atua na manutenção da ordem, trabalha os aspectos da disciplina, da ética e respeito, contribuindo com a eficácia na modernização do sistema de ensino e nas proposições de estratégias que busquem a excelência no processo de ensino e aprendizagem. Cada vez mais é percebida a importância desta alternativa de 
relação entre a escola e outros órgãos, com a finalidade de unir forças e estabelecer proteção às crianças e adolescentes.

Portanto, paira sobre esta ação colaborativa institucional, a missão de estruturar uma escola voltada para a modernização, para a ampliação dialógica, para a construção de uma pedagogia de projetos que proporcione emancipação. Preparando-os, assim, para enfrentarem os vestibulares e concursos, conquistarem espaços de sucesso no mercado de trabalho, serem cidadãos de bem, que construam suas histórias colaborando com a construção de uma sociedade justa, prospera, de respeito ao próximo.

A Escola cívico - militar, construída sob o viés do compartilhamento das autoridades educacionais, militares e em conjunto com a sociedade civil, propicia um debate sobre a possibilidade do bom desenvolvimento das crianças e jovens no país. Faz-se necessário enfatizar que direcionar o olhar para o papel da intersecção entre a comunicação, educação, novas tecnologias e segurança, pavimenta caminhos para o debate social acerca dos enfrentamentos na sociedade, vislumbrando, portanto, equacionar problemáticas e mobilizar aspectos formadores.

\section{CONSIDERAÇÕES FINAIS}

A escola é um organismo vivo de intensa mobilização dos sentidos e dos valores. É a referência em uma comunidade, no que tange à construção da subjetividade humana. E é, justamente esta agência de socialização tão estratégica que vem, ao longo dos anos, sendo alvo de diversos fenômenos a serem decodificados. A princípio, a falta de estrutura (muitas escolas encontram-se sucateadas); também há o aspecto do sistema pedagógico, que necessita do advento de tecnologias e inserções sempre diferenciadas para atender o aluno contemporâneo; a desestrutura dialógica com famílias (que, em muitos casos, não contribuem de forma colaborativa com a escola no processo de formação das crianças e adolescentes). A escola também enfrenta a falta de recursos, de apoio em várias vertentes, salários 
baixos para os professores e colaboradores e sofrem, também, com a elevação do índice de violência.

Assim como o êxito do PROERD chamou a atenção durante tanto tempo pela mobilização de ações afirmativas com crianças e adolescentes, os projetos que se aportam na proposta das escolas Cívico-Militares, atendem aspectos bastante semelhantes, mas, com um aprofundamento e diálogo mais intenso. A interface entre os campos da comunicação/educação/tecnologias apresenta-se como elemento chave no planejamento, execução e avaliação de todo o processo ensinoaprendizagem, isto é, a gestão da comunicação (a análise do processo dialógico) é parte integrante da gestão de projetos educacionais e, fundamenta, portanto, possibilidades instrumentais para a Escola Cívico-Militar.

A escola contemporânea exige transformações curriculares que vão desde o planejamento até a avaliação, passando pela formação profissional, pelo debate sobre a relação com a família e a comunidade externa, além do âmbito das relações em situações de tensão e conflitos.

A educação hoje vive o desafio de desenvolver-se sob "novos" princípios, de reconstruir-se sob um novo paradigma. Não mais é possível adotar currículos tradicionalistas. A sociedade da informação, das novas tecnologias, o novo aluno que adentra à sala de aula, é uma sociedade em rede, que impõe novas demandas aos indivíduos exigindo que sejam abertos às informações que surgem a cada momento. As tecnologias são realidades que alteram os sentidos e constroem novas alternativas de emancipação educacional. No que tange a proposta da Educomunicação para as Escolas Cívico-Militares, firma-se, portanto, um recurso didático e instrumental que pode contribuir com a ampliação do diálogo e entendimento, nas perspectivas dos sentidos sobre a construção do saber nestes espaços.

\section{REFERÊNCIAS}


CITELLI, Adilson. Comunicação e educação: a linguagem e movimento. São Paulo: Senac, 1999.

FERREIRA, Neusa Sousa Rêgo. "Gestão militar" da escola pública em Goiás: um estudo de caso da implementação de um Colégio Estadual da Polícia Militar de Goiás em Aparecida de Goiânia. 196 f. Dissertação (Mestrado em Educação). Goiânia: UFG, 2018.

LIMA, Maria Eliene. A educação para a cidadania e a militarização para a educação. 2018. 187 f. Dissertação ( Mestrado em Educação) Goiânia: PUCGoiás, 2018.

REGO, Teresa Cristina. Vigotski - Uma perspectiva histórico-cultural da educação. Petrópolis: Vozes, 1998.

REGO, Teresa Cristina. Vigotski - Uma perspectiva histórico-cultural da educação. Petrópolis: Vozes, 1998.

SANTOS, E. C. R., Conceito de Segurança Pública. Faculdade de Direito do Sul de Minas: Pouso Alegre, 2006

SCHAUN, Ângela. Educomunicação. Reflexões e princípios. Rio de Janeiro: Mauad, 2002.

SOARES, Ismar de Oliveira. "Educomunicação: as perspectivas do reconhecimento de um novo campo de intervenção social, o caso dos Estados Unidos". Revista ECCOS. São Paulo: Centro Universitário Uninove, v. 2, n. 2, dez. 2000

VASCONCELLOS, Celso dos Santos. Disciplina: construção da disciplina consciente e interativa em sala de aula e na escola. São Paulo: Libertad, 1994.

WALLON, H. A evolução psicológica da criança. Lisboa: Edições 70, 1968. 
Enviado: Março, 2021.

Aprovado: Maio, 2021. 